\title{
Residential exposure to solar ultraviolet radiation and incidence of childhood hematological malignancies in France
}

Astrid Coste $^{1}$, Stéphanie Goujon ${ }^{1,2}$, Mathieu Boniol ${ }^{3}$, Fabienne Marquant ${ }^{1}$, Laure Faure ${ }^{1,2}$, JeanFrançois Doré ${ }^{4}$, Denis Hémon ${ }^{1}$, Jacqueline Clavel $^{1,2}$

${ }^{1}$ Epidemiology and Biostatistics Sorbonne Paris Cité Center (CRESS), INSERM, UMR 1153, Epidemiology of childhood and adolescent cancers research group (EPICEA), Paris Descartes University, F-75014 Paris, France

${ }^{2}$ French National Registry of Childhood Hematological Malignancies (NRCH), Villejuif, France

${ }^{3}$ University of Strathclyde Institute of Global Public Health at iPRI, International Prevention Research Institute, Lyon, France

${ }^{4}$ Cancer Research Center of Lyon (CRCL), INSERM UMR 1052 CNRS 52B6, Centre Léon Bérard, 28 rue Laënnec, F-69373 Lyon Cedex 08, France

\section{Abbreviations:}

UV: ultraviolet; CHM: childhood hematological malignancies; AL: acute leukemia; ALL: acute lymphoblastic leukemia; AML: acute myeloid leukemia; PBC-ALL: precursor B-cell acute lymphoblastic leukemia; NHL: Non-Hodgkin's lymphoma; HL: Hodgkin's lymphoma

Key words: ultraviolet radiation; sun exposure; children; hematological malignancies

Correspondence:

Astrid Coste, PhD student, Epidemiology of childhood and adolescent cancers research group (EPICEA), Epidemiology and Biostatistics Sorbonne Paris Cité Center (CRESS), INSERM, UMR 1153, Paris Descartes University, F-75014 Paris, France, Tel:+33145595292, Fax: +33145595151, Email:astrid.coste@inserm.fr

Original paper/Cancer research/Epidemiology 


\section{Abstract 246 Words}

Purpose Few studies have investigated the relationship between solar ultraviolet radiation (UV) and childhood hematological malignancies (CHM). This study addresses the associations between residential UV exposure at diagnosis and the incidence of types and subtypes of $\mathrm{CHM}$, by age and gender, in France, over a long period, on the fine scale of the 36,326 Communes that constitute mainland France. Methods The 9,082 cases of acute leukemia (AL) and 3,563 cases of lymphoma diagnosed before the age of 15 years from 1990 to 2009 were provided by the French National Registry of Childhood Hematological Malignancies. The incidence of $\mathrm{CHM}$ was calculated by Commune, year, age and gender and expressed as the standardized incidence ratio (SIR). UV data from 1988 to 2007 were extracted from the EUROSUN database. Results The annual daily average UV exposure of the children ranged from 85.5 to $137.8 \mathrm{~J} / \mathrm{cm}^{2}$. For each additional $25 \mathrm{~J} / \mathrm{cm}^{2}$ there was a significant increase in precursor B-cell acute lymphoblastic leukemia (PBC-ALL) in children aged less than 5 years (SIR: $1.18 ; 95 \% \mathrm{Cl}: 1.10-1.27)$. Further analysis of PBC-ALL in the young children suggested a better fit of models with a threshold, with the risk increasing above $100 \mathrm{~J} / \mathrm{cm}^{2}$, for which the SIR was 1.24 (95\% Cl: 1.14-1.36) for a $25 \mathrm{~J} / \mathrm{cm}^{2}$ increase. The results remained stable in analyses stratifying by deprivation index or degree of urbanization of the Communes. Conclusion The study suggests that higher residential UV exposure may be positively associated with a higher incidence of PBC-ALL in early childhood.

\section{Introduction}

Acute leukemia (AL) and lymphoma are the most frequent childhood hematological malignancies (CHM). Several genetic diseases and polymorphisms[1], and non-genetic exposures (including ionizing radiation and, for Hodgkin's and Burkitt's lymphoma, Epstein Barr virus) are known risk factors. Some factors related to early immune stimulations and environmental exposures (pesticide use at home and, for AL, extremely low frequency electromagnetic fields) are also suspected[2, 3].

Solar ultraviolet (UV) radiation, UVA (315-400 nm) and UVB (280 - $315 \mathrm{~nm})$, exposures are ubiquitous with marked gradients within and between countries.

Solar UV radiation, a known risk factor for skin cancers[4], plays a role in vitamin D synthesis and, through this mechanism, has also been identified as a potential protective factor for some cancers $[5$, 6]. UV radiation, especially UVB radiation, may also induce systemic immune suppression. Animal study findings have raised the question of whether UV radiation may influence the development of hematological malignancies by means of its immunosuppressive effect[7-9].

The effects of UV radiation on human health are multiple and complex, and may act in positive or negative ways on the emergence of hematological malignancies. The general population's exposure to solar UV radiation is known to have increased in recent decades. In addition to experimental biological investigations of the association between UV radiation and the incidence of hematological malignancies, the results of which are still not conclusive, epidemiological studies have been conducted. The results are mixed for adults and only four studies have been published for children.

The association between the incidence of non-Hodgkin's lymphoma (NHL) and UV radiation exposure among adults has been much studied in the last 20 years. However, the results remain a subject of debate. Most North-American studies and a few others, including pooled studies, have found an inverse association between UV radiation exposure and NHL incidence[10-13]. However, some studies found a positive association[14-16]. There have been few studies of leukemia and Hodgkin's lymphoma, and UV radiation exposure. Most of the studies conducted have found an inverse association between UV radiation and cancer incidence [17-20]. An ecological study in Japan found a positive correlation between UVB radiation level and leukemia mortality risk, but only for two 
subtypes: 'lymphoid leukemia' and 'other malignant neoplasms of lymphoid and histiocytic tissue'[21].

To the authors' knowledge, four studies, with different designs and sample sizes, on the association between childhood hematological malignancies and UV radiation exposure have been published. Three studies found a negative association, for leukemia $[22,24]$ and/or NHL $[23,24]$, while the fourth study [25] showed an increased risk of lymphoblastic leukemia in 2-4-year-old children during the light season (April-September).

In that context, the objective of the present study was to analyze the association between population exposure to UV radiation and the incidence of types and subtypes of $\mathrm{CHM}$, over a long time period.

\section{Materials and Methods}

The association between the UV exposure of the subjects' places of residence at the time of diagnosis and the incidence rates of $\mathrm{CHM}$ was studied. For this purpose, quantitative estimates of average annual exposures to UV radiation for the 1988-2007 period of the 36,326 French Communes, the smallest administrative subdivisions of the country, were associated with the incidence data of the corresponding Communes of France by year, age and gender.

\section{Cases, time period, geographic units and population counts}

The CHM cases were provided by the French National Registry of Childhood Hematological Malignancies (NRCH)[26]. Since 1990, the registry has included all the malignant or borderline hematological diseases occurring in children aged less than 15 years residing in mainland France at the time of diagnosis. For each case, the registry provided the date of birth, date of diagnosis and address where the child was living at the time of diagnosis. All the CHM cases diagnosed between 1990 and 2009 and having a known residential Commune at diagnosis were included $(99.9 \%$ of the cases). For the study period (1990-2009), 9,082 cases of AL and 3,563 cases of lymphoma were included.

An incidence study was performed at the Commune level over the study period. The cases consisted in all children diagnosed with AL or lymphoma before the age of 15 years and registered in the NRCH during the period. The annual national $\mathrm{CHM}$ incidence rates estimated by the $\mathrm{NRCH}$, by age and gender, were used as reference rates. The annual estimates of the Commune populations, by year of age and gender, were provided by the French National Institute for Statistics and Economic Research (INSEE) for the census years: 1990, 1999, 2006, 2007, 2008 and 2009. For the other years, the estimates for the Communes were interpolated using the annual estimates provided by INSEE for the 96 French mainland Départements (larger administrative units with an average of 360 Communes per Département).

\section{UV radiation exposure at the time of diagnosis}

UV radiation exposure data were provided by the European EUROSUN project, the aims of which are to quantify sun exposure in Europe and its effects on health. The European Meteosat satellites provided images from which an assessment of solar surface irradiance (SSI) was obtained for the 1988-2007 period (HelioClim-1 database for 1988-2005, HelioClim-3 database for 2004-2007). SSI is the solar irradiance observed at ground level on horizontal surfaces and is integrated over the whole spectrum[27]. An algorithm enables derivation of the spectral distribution every $10 \mathrm{~nm}$ from the total irradiance observations. The EUROSUN data provide an assessment of UVA and UVB radiation in Europe on a $5 \times 5 \mathrm{~km}$ grid. Each Commune was allocated the annual average UVA and UVB radiation estimated at the location of the town hall. The spatial correlation between UVB and UVA radiation exposures was almost equal to 1 . Consequently, the associations of UVA and UVB radiation exposures with $\mathrm{CHM}$ could not be analyzed separately and the exposure variable used for a given 
Commune was therefore the daily average UV (UVA+UVB) radiation exposure over the period 19882007.

\section{Statistical analysis}

All analyses were implemented with SAS v9.3 software.

The standardized incidence ratio (SIR) was used to characterize the spatial differentials of incidence over the study period. The SIR was calculated as the ratio of the observed number of cases to the corresponding expected number of cases obtained from the Commune numbers of at-risk personyears (PY), by age (1 year) and gender, and the national annual age- and gender-specific incidence rates.

Poisson regressions were fitted for all the analyses using the Communes of residence at diagnosis as the basic statistical unit, with their expected number of cases $\left(E_{i}\right)$ as the offsets and observed number of cases $\left(\mathrm{O}_{\mathrm{i}}\right)$ as the observations. As most of the analyses which were performed on this small scale led to under-dispersion, Communes were grouped using the decile of the covariate of interest.

Since there were no prior hypotheses with regard to the shape of the relationship between leukemia or lymphoma incidence and sun exposure, two models were compared using the log-likelihood test to determine the degree of adequacy of a log-linear association. In the first model, the UV radiation exposure variable was qualitative and categorized to obtain UV radiation based geographic zoning, which consisted of 10 groups of Communes ("deciles") $D_{k}, k=1, \ldots, 10$ with equal pediatric populations (0-14 years):

$$
\ln E\left(O_{k}\right)=\ln \left(E_{k}\right)+\sum_{h=1}^{10} \beta_{h} \cdot X_{h}
$$

In which:

- $E\left(O_{k}\right)$ is the expected value of the observed number of cases $\left(O_{k}\right)$ in decile $D_{k}$ of the Communes, and $E_{k}$ is the expected number of cases,

- $X_{h}$ is an indicator variable with a value of 1 for decile $D_{h}$ and 0 for the other deciles, and $\beta_{h}$ is the corresponding regression coefficient.

For the second model, a semi-quantitative discrete UV radiation variable was built:

$$
\ln E\left(O_{k}\right)=\ln \left(E_{k}\right)+\alpha_{0}+\beta \cdot U V_{k}
$$

in which $U V_{k}$ is the pediatric population weighted average value of the UV radiation exposure in decile $D_{k}$. In this model, $e^{\beta}$ estimated the SIR variation with an increase of $1 \mathrm{UV}$ radiation unit. In this study, one UV radiation unit is equal to an increase of $25 \mathrm{~J} / \mathrm{cm}^{2}$, which is about half of the UV radiation range for the Communes.

A value of the deviance/degrees of freedom ratio greater than 2 was considered to indicate an overdispersed model. In the event of over-dispersion that was not explained by a more adequate model, a negative binomial error was used instead of the Poisson error.

Considering the shape of some of the associations between $U V_{k}$ and the SIR, even when log-linearity was not formally rejected, a model with a segmented linear regression with one change point $(\tau)$ was also fitted to some observed CHM counts:

$$
\ln E\left(O_{k}\right)=\ln \left(E_{k}\right)+\alpha_{1}+\beta \cdot\left(U V_{k}-\tau\right)^{+},
$$


in which $U V_{k}$ is the pediatric population weighted average value of the UV radiation exposure in the decile, $D_{k},\left(U V_{k}-\tau\right)^{+}$is the positive part of $\left(U V_{k}-\tau\right)$ which takes the value zero if $U V_{k} \leq \tau$ and $\left(U V_{k^{-}} \tau\right)$ otherwise. In order to determine whether there was convincing evidence of a change point and determine the best change point, segmented linear regressions were fitted to the observations with values of $\tau$ every $2 \mathrm{~J} / \mathrm{cm}^{2}$ and the AIC criterion was used to identify the best model.

The regression models included no term of spatial autocorrelation even though exposures to UV are spatially correlated, since previous analyses of the data had not shown any spatial auto-correlation between CHM rates in France[28-30].

Analyses were performed by type and subtype of $\mathrm{CHM}$, by age group and gender. The study had a statistical power of $80 \%$ for underlying exact SIR less than 0.85 or greater than 1.15 for most types of CHM with a two-sided Poisson test at the $5 \%$ level for a general pediatric population exposure frequency of $10 \%$.

The stability of the results was first assessed by examining their consistency across three time periods (1990-1996, 1997-2003, 2004-2008) and five large geographic subdivisions of France (Paris area, North-West, North-East, South-East, South-West).

In order to account for potential confounding or effect modification, analyses were repeated after stratification by, or adjustment for, the urban status and socio-demographic characteristics of the Communes extracted from the 1999 census data. The French deprivation index FDep99[31] was defined as the first component ( $68 \%$ of the total variation) of a principal component analysis of four census variables: median income of the households, proportion of blue-collar workers, proportion of unemployed and proportion of baccalaureate (high school diploma) holders.

In a parallel analysis, the correlation between Commune sun exposure at birth and at diagnosis was estimated with data from two national population-based case-control studies conducted by the authors' team. The ESCALE study was conducted between 2003 and 2004 and included $763 \mathrm{AL}$ cases and 1,681 controls [32]. The ESTELLE study was conducted between 2010 and 2011 and included 747 AL cases and 1,421 controls [33].

\section{Results}

UV (UVA+UVB) radiation exposure varied between 85.5 and $137.8 \mathrm{~J} / \mathrm{cm}^{2}$ with a median of 100.2 $\mathrm{J} / \mathrm{cm}^{2}$. A clear north-south gradient of UV radiation exposure was observed, together with locally slightly higher UV radiation exposures in the Paris area and Alsace region (Figure 1).

The main subtypes of leukemia were acute lymphoblastic leukemia (ALL), which accounted for $82.0 \%$ of all AL and acute myeloid leukemia (AML), which accounted for $16.3 \%$ of all AL (Table 1). The lymphomas consisted in 58.7\% non-Hodgkin's lymphoma (NHL) and $41.3 \%$ Hodgkin's lymphoma.

UV radiation exposure was positively associated with the incidence of AL (Table 2), with a significant log-linear trend. The association was limited to ALL, with a 9\% increase in SIR (SIR=1.09;95\% CI [1.031.14]) for an increase of $25 \mathrm{~J} / \mathrm{cm}^{2}$. A positive linear trend was found and was borderline significant for $\mathrm{NHL}$, particularly the Burkitt subtype. However, the overall heterogeneity test for the ten deciles of exposure was clearly not significant (Table 3).

Age at diagnosis significantly interacted with UV radiation exposure $(p=0.007)$. The association between UV radiation exposure and ALL was only observed for children aged less than 5 years $(\mathrm{SIR}=1.16 ; 95 \% \mathrm{Cl}$ [1.08-1.25]) (Supplementary table A). For the children aged more than 5 years, the SIR was almost equal to 1 and not significant. In contrast, gender had no significant modifying effect (Supplementary table B). 
The results were also heterogeneous across the three main subtypes of ALL $(p=0.036)$. A positive and still very highly significant association only remained for PBC-ALL, the most common ALL subtype with 5,977 cases (Table 2). The modifying effect of age at diagnosis also remained significant for PBCALL $(p=0.035)$ (Table 4). A positive linear trend, borderline significant, was found for the 10-14 years age group. However, the heterogeneity test was not significant and the shape of the association was quite different from that of the $0-4$ years age group.

The association between UV radiation exposure and the incidence of PBC-ALL in young children did not seem to be linear over the whole range of UV radiation exposure since the SIR were significantly greater than 1 only in the last three UV radiation exposure deciles (Table 4). Threshold log-linear Poisson regressions were adjusted with various possible values of the threshold and the clearly bestfit with the data was obtained with a threshold value of $100 \mathrm{~J} / \mathrm{cm}^{2}$. The corresponding SIR was $1.24\left(95 \% \mathrm{Cl}\right.$ [1.14-1.36]) for a $25 \mathrm{~J} / \mathrm{cm}^{2}$ difference in UV exposure among Communes exposed to $100 \mathrm{~J} / \mathrm{cm}^{2}$ or more (Table 4 and Supplementary figure).

The associations observed between residential UV radiation exposure and PBC-ALL diagnosed before age 5 years in the three time periods (1990-1996, 1997-2003, 2004-2009) were very similar, and no modifying effect of time period on the association between UV radiation exposure and PBC-ALL diagnosed before age 5 years was observed (Table 5).

Analyzing this association across 5 large French regions (North-East, Paris area, North-West, SouthWest, South-East) showed that it was positive and significant in the South-East region (SIR $=1.25$; $95 \% \mathrm{Cl}[1.07,1.45])$, where UV radiation exposure is both greater on average than in the other regions and more variable (Table 5). In the South-West and North-West, the association was positive but not statistically significant. The UV radiation exposure variability in the Paris area was so limited that it could not be considered separately. This was also practically the case for the North East region, where the population exposed to more than $100 \mathrm{~J} / \mathrm{cm}^{2}$ was very small $(2.7 \%)$. However, when the South-East was excluded, the association between PBC-ALL diagnosed before age 5 years and UV radiation exposure was positive and significant (SIR: 1.46; $95 \% \mathrm{CI}$ [1.14-1.87] for a 25-unit increase in UV above $100 \mathrm{~J} / \mathrm{cm}^{2}$ ). Overall, there was no statistically significant modifying effect of the UV radiation PBC-ALL association by region $(p=0.63)$.

A significant log-linear trend between PBC-ALL incidence and a French deprivation index (Fdep) was observed, with a slightly higher incidence of PBC-ALL before age 5 years in less deprived Communes $(p=0.03)$. No modifying or confounding effect of this variable on the association between Commune UV radiation exposure and PBC-ALL diagnosed before age 5 years was evidenced. Sensitivity analyses on the South East of France, the region with the highest and most variable UV radiation exposure, which was also the region where the Fdep was most associated with PBC-ALL, did not show any modifying effect of Fdep on the association between UV radiation exposure and PBC-ALL (data not shown).

No association between PBC-ALL and urban status was observed $(p=0.51)$. No modifying or confounding effect of urban status on the association between UV radiation exposure and PBC-ALL before age 5 years was observed (data not shown).

Considering the ESCALE and ESTELLE case-control data, a strong correlation ( $r$ ) between the sun exposure of the Commune of residence of the controls at birth and that of their Commune of residence at inclusion in the study was found, especially for the youngest children (aged less than 5 years) ( $r=+0.90$ for ESCALE and ESTELLE). 


\section{Discussion}

There was a positive association between the Commune spatial variability of UV radiation exposure and that of the incidence of PBC-ALL for the children aged less than 5 years in France for the period 1990-2009. No significant association was evidenced for the other CHM or at other ages. The association observed was the same for both genders, and was not modified by time period. No regional heterogeneity was observed. Stratification by, or adjustment for, a French deprivation index (Fdep99) and an urban unit variable did not significantly change the association between UV radiation exposure and the incidence of PBC-ALL in young children.

The power of the comparisons was evaluated a priori to be greater than $80 \%$ for SIR less than 0.85 or greater than 1.15 for most types of $\mathrm{CHM}$, for a frequency of exposure of $10 \%$. Even though multiple comparisons were performed by studying the association for each type of $\mathrm{CHM}$, subtype of leukemia, age group, gender, and some potential confounding factors, the statistical significance level of the association and its consistency with respect to several stratifications do not suggest a random association.

The strengths of this study consist in the objectivity of the sun exposure data, available on a fine scale (Communes), and the exhaustiveness and high quality of the incidence data, and the long time period studied, which enabled large numbers of CHM cases to be studied by type and subtype. The population studied was relatively homogeneous and lived over a large area with a fairly wide distribution of UV radiation exposures.

Because of the very high spatial correlation between UVA and UVB, it was not possible to distinguish their associations with $\mathrm{CHM}$.

Although the Commune UV radiation exposures were highly auto-correlated, an auto-correlated structure for the observed Poisson count was not considered relevant as the dependent variable was not spatially auto-correlated in any of the studies conducted in France. The small yearly variations in CHM incidence that had previously been observed[34] were taken into account in the estimates of the expected number of cases for each Commune.

As a result of the highly auto-correlated and smooth continuous spatial variation of Commune sun exposure, the sun exposure in the Commune of residence at inclusion in the study for the controls, was very closely correlated with that of the Commune of birth in two large population based casecontrol studies conducted by the authors' team on the same population of children (ESCALE: 20032004 and ESTELLE: 2010-2011). It is therefore unlikely that the findings of this study are dependent on considering the Commune at birth rather than the Commune at diagnosis. As a result, the association observed cannot be specifically related to a particular exposure time window for the children or their parents: before conception, during pregnancy, at birth, since birth, around diagnosis.

The present study detected a positive spatial correlation between a population exposure index, Commune sun exposure, and Commune PBC-ALL incidence in young children. Even though it is likely that this association does exist in the French pediatric population it may be either a direct individual association or, alternatively, reflect the effect of some other unknown individual or Commune characteristics, which are related to residential sun exposure and influence the incidence of this particular group of ALL. This is not the case for the increased incidence of children leukemia that has been observed in France in the close vicinity of nuclear power plants[35] or high voltage power lines[3]. Both increased incidences are very localized spatially and cannot explain the trend association found in this study.

Of the four studies published on the association between residential sun exposure and CHM, three used very different methods, populations or exposure variables, compared to those used herein. The 
international study conducted by Musselman and Spector [22] found an inverse association between sun exposure and leukemia (lymphoid and acute non-lymphocytic leukemia), and, after adjusting on a socioeconomic index, no significant association with lymphoma, as in the present study. The exposure was assessed by the absolute latitude and by an annual solar radiation measurement based on NASA data. The study was conducted on a very large scale, in 57 countries (some partially covered), located on different continents. The Greek study [23] found an inverse association between NHL and individual sun exposure. The study was based on interviews and measured individual sun exposure in a country with a very different level of UV radiation exposure to that in France. In addition, the association reported was based on a limited number of subjects ( $87 \mathrm{NHL}$ cases, 164 controls). A large Finnish study [25], which included 7,423 cases between 1964 and 2003, both adults and children, found, in a subgroup analysis, lower numbers of ALL in the dark season among children aged 2-4 years. The results were quite similar to those of the present study.

The study[24] most similar to the present study in terms of methods and power was a large Californian study, which included 10,476 cases and 207,568 controls. The exposure assessment was ecological and obtained from a geostatistical model that estimated ground level UV radiation from UV radiation measurement station data. An inverse relationship was found for ALL and NonHodgkin's lymphoma for children 0-5 years old. In contrast, the present study showed a significant positive association between sun exposure at diagnosis and PBC-ALL in young children (less than 5 years old) and no significant association with lymphoma. The Californian study analyzed sun exposure at birth and it may be that the correlation between sun exposure at birth and at diagnosis for the Californian children is not as strong as that observed in France. Furthermore, California has a different level of UV radiation exposure than France, as the maximum yearly average residential exposure to sun in France $(137.8 \mathrm{~J} / \mathrm{cm} 2)$ is less than the first quartile of exposure in the Californian study $(148.4 \mathrm{~J} / \mathrm{cm} 2)$. In addition, large fractions of the Californian population have different skin pigmentations and lifestyles. These may also contribute to explaining the different results. The Californian study recorded data on 'ethnicity' and the authors found a negative association with UV radiation exposure for children with Hispanic mothers (Hispanics were the largest ethnic group in the study) and African-American mothers, but not for children with Caucasian mothers. In the present study, no information on 'ethnicity' was available, but the majority of the French population is of Caucasian origin.

\section{Conclusion}

This study suggests a positive geographic association between population residential UV radiation exposure greater than $100 \mathrm{~J} / \mathrm{cm}^{2}$ and the incidence of PBC-ALL, essentially for children under the age of 5 years. The systemic immune suppression induced by UV radiation may be a biological hypothesis for this finding. However, further ecological studies are necessary in order to replicate this result in other populations and investigate whether these findings are due to other spatially heterogeneous ecological factors that are associated with both population residential sun exposure and the particular subgroup of ALL. An additional question is whether there is an association between the individual UV radiation exposure of the child/mother/father and the risk of CHM. Investigation for such an association could only be conducted in the context of individual case-control studies and, possibly, sufficiently large cohort studies, which include precise individual information on exposure to sun and take into account individual childhood leukemia risk factors potentially associated with individual UV radiation exposure. Future studies should also address residential history, skin type and other factors that may be correlated with UV radiation exposure. Meanwhile, irrespective of whether the association is direct or not, it should be considered and taken into account in other spatial studies of the variability of childhood leukemia incidences rates in relation to other factors including environmental and behavioral factors. 


\section{Acknowledgments}

This study was supported by the 'Institut de Veille Sanitaire' (InVS), 'Agence Nationale de Sécurité Sanitaire de l'Alimentation, de l'Environnement et du Travail' (ANSES; EST-2013/1/205), 'Association pour la recherche sur le cancer' (ARC), 'Institut National du Cancer' (INCa), which provided financial support to the 'Plateforme de recherche sur les cancers de l'enfant', 'Agence Nationale de la Recherche' (ANR) and 'Cancéropôle Ile-de-France'. It is part of the 'Investissement d'Avenir' HOPE-EPI program supported by the ANR. The authors are particularly grateful to all the NRCH research assistants who collected the cases' data and the pediatric oncology teams for their help in data collection. 



\section{References}

1. Orsi L, Rudant J, Bonaventure A, et al. (2012) Genetic polymorphisms and childhood acute lymphoblastic leukemia: GWAS of the ESCALE study (SFCE). Leukemia 26:2561-2564. doi: 10.1038/leu.2012.148

2. Rudant J, Menegaux F, Leverger G, et al. (2007) Household Exposure to Pesticides and Risk of Childhood Hematopoietic Malignancies: The ESCALE Study (SFCE). Environ Health Perspect 115:1787-1793. doi: 10.1289/ehp.10596

3. Sermage-Faure C, Demoury C, Rudant J, et al. (2013) Childhood leukaemia close to high-voltage power lines - the Geocap study, 2002-2007. Br J Cancer 108:1899-1906. doi: 10.1038/bjc.2013.128

4. INTERNATIONAL AGENCY FOR RESEARCH ON CANCER (1992) IARC monographs on the evaluation of carcinogenic risks to humans. Solar and ultraviolet radiation. IARC Monogr Eval Carcinog Risks Hum.55:1-316

5. Autier P, Boniol M, Pizot C, Mullie P (2014) Vitamin D status and ill health: a systematic review. Lancet Diabetes Endocrinol 2:76-89. doi: 10.1016/S2213-8587(13)70165-7

6. Doré J-F, Chignol M-C (2014) Vitamin D and Cancer. OCL 21:D306. doi: 10.1051/ocl/2013058

7. INTERNATIONAL PROGRAMME ON CHEMICAL SAFETY (1994) Ultraviolet radiation. EHC Monographs 160

8. Jiang W, Ananthaswamy HN, Muller HK, et al. (2001) UV irradiation augments lymphoid malignancies in mice with one functional copy of wild-type p53. Proc Natl Acad Sci U S A 98:9790-9795. doi: 10.1073/pnas.171066498

9. Puebla-Osorio N, Miyahara Y, Coimbatore S, et al. (2011) Induction of B-cell lymphoma by UVB Radiation in p53 Haploinsufficient Mice. BMC Cancer 11:36. doi: 10.1186/1471-2407-11-36

10. Freedman DM, Zahm SH, Dosemeci M (1997) Residential and occupational exposure to sunlight and mortality from non-Hodgkin's lymphoma: composite (threefold) case-control study. BMJ 314:1451. doi: 10.1136/bmj.314.7092.1451

11. Kricker A, Armstrong BK, Hughes AM, et al. (2008) Personal sun exposure and risk of non Hodgkin lymphoma: A pooled analysis from the Interlymph Consortium. Int J Cancer 122:144-154. doi: $10.1002 /$ ijc. 23003

12. Wong K-Y, Tai B-C, Chia S-E, et al. (2012) Sun exposure and risk of lymphoid neoplasms in Singapore. Cancer Causes Control 23:1055-1064. doi: 10.1007/s10552-012-9974-1

13. Cahoon EK, Pfeiffer RM, Wheeler DC, et al. (2015) Relationship between ambient ultraviolet radiation and non-Hodgkin lymphoma subtypes: A U.S. population-based study of racial and ethnic groups. Int J Cancer 136:E432-E441. doi: 10.1002/ijc.29237

14. Bentham G (1996) Association between incidence of non-Hodgkin's lymphoma and solar ultraviolet radiation in England and Wales. BMJ 312:1128-1131. doi: 10.1136/bmj.312.7039.1128

15. Grandin L, Orsi L, Troussard X, et al. (2008) UV radiation exposure, skin type and lymphoid malignancies: results of a French case-control study. Cancer Causes Control CCC 19:305-315. doi: 10.1007/s10552-007-9093-6

16. Bertrand KA, Chang ET, Abel GA, et al. (2011) Sunlight exposure, vitamin D, and risk of nonHodgkin lymphoma in the Nurses' Health Study. Cancer Causes Control CCC 22:1731-1741. doi: 10.1007/s10552-011-9849-x

17. Grant WB, Garland CF (2006) The Association of Solar Ultraviolet B (UVB) with Reducing Risk of Cancer: Multifactorial Ecologic Analysis of Geographic Variation in Age-adjusted Cancer Mortality Rates. Anticancer Res 26:2687-2699.

18. Boscoe FP, Schymura MJ (2006) Solar ultraviolet-B exposure and cancer incidence and mortality in the United States, 1993-2002. BMC Cancer 6:264. doi: 10.1186/1471-2407-6-264

19. Mohr SB, Garland CF, Gorham ED, et al. (2011) Ultraviolet B and Incidence Rates of Leukemia Worldwide. Am J Prev Med 41:68-74. doi: 10.1016/j.amepre.2011.04.003 
20. Monnereau A, Glaser SL, Schupp CW, et al. (2013) Exposure to UV radiation and risk of Hodgkin lymphoma: a pooled analysis. Blood 122:3492-3499. doi: 10.1182/blood-2013-04-497586

21. Uehara M, Takahashi K, Hoshuyama T, et al. (2003) Geographical correlation between ambient UVB level and mortality risk of leukemia in Japan. Environ Res 92:78-84. doi: 10.1016/S00139351(03)00034-3

22. Musselman JRB, Spector LG (2010) Childhood cancer incidence in relation to sunlight exposure. $\mathrm{Br}$ J Cancer 104:214-220. doi: 10.1038/sj.bjc.6606015

23. Petridou ET, Dikalioti SK, Skalkidou A, et al. (2007) Sun exposure, birth weight, and childhood lymphomas: a case control study in Greece. Cancer Causes Control 18:1031-1037. doi: 10.1007/s10552-007-9044-2

24. Lombardi C, Heck JE, Cockburn M, Ritz B (2013) Solar UV radiation and cancer in young children. Cancer Epidemiol Biomark Prev Publ Am Assoc Cancer Res Cosponsored Am Soc Prev Oncol 22:1118-1128. doi: 10.1158/1055-9965.EPI-12-1316

25. Timonen T, Näyhä S, Koskela T, Pukkala E (2007) Are sunlight deprivation and influenza epidemics associated with the onset of acute leukemia? Haematologica 92:1553-1556. doi: 10.3324/haematol.10799

26. Lacour B, Guyot-Goubin A, Guissou S, et al. (2010) Incidence of childhood cancer in France: National Children Cancer Registries, 2000-2004: Eur J Cancer Prev 19:173-181. doi: 10.1097/CEJ.0b013e32833876c0

27. Blanc P, Gschwind B, Lefèvre M, Wald L (2011) The HelioClim Project: Surface Solar Irradiance Data for Climate Applications. Remote Sens 3:343-361. doi: 10.3390/rs3020343

28. Bellec S, Hémon D, Rudant J, et al. (2006) Spatial and space-time clustering of childhood acute leukaemia in France from 1990 to 2000: a nationwide study. Br J Cancer 94:763-770. doi: 10.1038/sj.bjc.6602980

29. Faure C, Mollié A, Bellec S, et al. (2009) Geographical variations in the incidence of childhood acute leukaemia in France over the period 1990-2004: Eur J Cancer Prev 18:267-279. doi: 10.1097/CEJ.0b013e32832bf43a

30. Demoury C, Goujon-Bellec S, Guyot-Goubin A, et al. (2012) Spatial variations of childhood acute leukaemia in France, 1990-2006: global spatial heterogeneity and cluster detection at "livingzone" level. Eur J Cancer Prev 21:367-374. doi: 10.1097/CEJ.0b013e32834e31d8

31. Rey G, Jougla E, Fouillet A, Hémon D (2009) Ecological association between a deprivation index and mortality in France over the period 1997 - 2001: variations with spatial scale, degree of urbanicity, age, gender and cause of death. BMC Public Health 9:33. doi: 10.1186/1471-24589-33

32. Amigou A, Sermage-Faure C, Orsi L, et al. (2011) Road Traffic and Childhood Leukemia: The ESCALE Study (SFCE). Environ Health Perspect 119:566-572. doi: 10.1289/ehp.1002429

33. Ajrouche R, Rudant J, Orsi L, et al. (2014) Maternal reproductive history, fertility treatments and folic acid supplementation in the risk of childhood acute leukemia: the ESTELLE Study. Cancer Causes Control 25:1283-1293. doi: 10.1007/s10552-014-0429-8

34. Goujon-Bellec S, Mollié A, Rudant J, et al. (2013) Time trends and seasonal variations in the diagnosis of childhood acute lymphoblastic leukaemia in France. Cancer Epidemiol 37:255261. doi: 10.1016/j.canep.2013.01.001

35. Sermage-Faure C, Laurier D, Goujon-Bellec S, et al. (2012) Childhood leukemia around French nuclear power plants-The geocap study, 2002-2007. Int J Cancer 131:E769-E780. doi: 10.1002/ijc. 27425 
Table 1: Distribution of childhood hematological malignancies, by age and gender (France 1990-2009)

\begin{tabular}{|c|c|c|c|c|c|c|c|c|c|c|c|c|}
\hline & \multicolumn{4}{|c|}{ Boys } & \multicolumn{4}{|c|}{ Girls } & \multicolumn{4}{|c|}{ Both } \\
\hline & $0-4$ years & $5-9$ years & $10-14$ years & Total & $0-4$ years & 5-9 years & $10-14$ years & Total & $0-4$ years & 5-9 years & $10-14$ years & Total \\
\hline \multicolumn{13}{|l|}{ Leukemia } \\
\hline ALL & 2030 & 1321 & 832 & 4183 & 1746 & 953 & 561 & 3260 & 3776 & 2274 & 1393 & 7443 \\
\hline$P B C-A L L$ & 1765 & 849 & 498 & 3112 & 1630 & 792 & 443 & 2865 & 3395 & 1641 & 941 & 5977 \\
\hline$B-A L L$ & 72 & 115 & 63 & 250 & 27 & 39 & 19 & 85 & 99 & 154 & 82 & 335 \\
\hline$T-A L L$ & 164 & 345 & 262 & 771 & 72 & 111 & 92 & 275 & 236 & 456 & 354 & 1046 \\
\hline AML & 351 & 171 & 226 & 748 & 343 & 175 & 210 & 728 & 694 & 346 & 436 & 1476 \\
\hline NOS AL & 45 & 28 & 29 & 102 & 30 & 18 & 13 & 61 & 75 & 46 & 42 & 163 \\
\hline Total & 2426 & 1520 & 1087 & 5033 & 2119 & 1146 & 784 & 4049 & 4545 & 2666 & 1871 & 9082 \\
\hline \multicolumn{13}{|l|}{ Lymphoma } \\
\hline $\mathrm{NHL}$ & 293 & 621 & 569 & 1483 & 132 & 216 & 260 & 608 & 425 & 837 & 829 & 2091 \\
\hline Lymphoblastic & 75 & 121 & 145 & 341 & 44 & 40 & 62 & 146 & 119 & 161 & 207 & 487 \\
\hline Burkitt & 167 & 357 & 239 & 763 & 46 & 85 & 59 & 190 & 213 & 442 & 298 & 953 \\
\hline Mature & 51 & 143 & 184 & 378 & 42 & 90 & 137 & 269 & 93 & 233 & 321 & 647 \\
\hline $\mathrm{HL}$ & 56 & 255 & 551 & 862 & 10 & 81 & 519 & 610 & 66 & 336 & 1070 & 1472 \\
\hline Total & 349 & 876 & 1120 & 2345 & 142 & 297 & 779 & 1218 & 491 & 1173 & 1899 & 3563 \\
\hline
\end{tabular}

AL: Acute leukemia; ALL: Acute lymphoblastic leukemia; AML: Acute myeloblastic leukemia; PBC-ALL: precursor B-cell ALL ; B-ALL: Burkitt-cell Leukemia;T-ALL: T-cell ALL; AL NOS : Not otherwise specified AL; HL: Hodgkin's lymphoma; NHL: non-Hodgkin's lymphoma 
Table 2: Incidence of childhood leukemia (ages 0-14) by decile of UV radiation exposure (France, 1990-2009)

\begin{tabular}{|c|c|c|c|c|c|c|c|c|c|c|c|c|}
\hline \multirow[b]{2}{*}{ UV radiation deciles $\left(\mathrm{J} / \mathrm{cm}^{2}\right)$} & \multicolumn{4}{|c|}{ Acute Leukemia (AL) } & \multicolumn{4}{|c|}{ Acute lymphoblastic leukemia (ALL) } & \multicolumn{4}{|c|}{ Acute myeloid leukemia (AML) } \\
\hline & 0 & $\mathrm{E}$ & SIR & $95 \% \mathrm{Cl}$ & 0 & $\mathrm{E}$ & SIR & $95 \% \mathrm{Cl}$ & 0 & $\mathrm{E}$ & SIR & $95 \% \mathrm{Cl}$ \\
\hline [85.5-90.3] & 923 & 913.4 & 1.01 & $0.95-1.08$ & 751 & 748.6 & 1 & $0.93-1.08$ & 159 & 148.6 & 1.07 & $0.92-1.25$ \\
\hline ]90.3-94.1] & 888 & 893.4 & 0.99 & $0.93-1.06$ & 725 & 732.2 & 0.99 & $0.92-1.06$ & 140 & 145.3 & 0.96 & $0.82-1.14$ \\
\hline ]94.1-97.2] & 888 & 904 & 0.98 & $0.92-1.05$ & 705 & 741.2 & 0.95 & $0.88-1.02$ & 159 & 146.7 & 1.08 & $0.93-1.27$ \\
\hline ]97.2-99.1] & 919 & 909.6 & 1.01 & $0.95-1.08$ & 739 & 745.6 & 0.99 & $0.92-1.07$ & 166 & 147.7 & 1.12 & $0.97-1.31$ \\
\hline ]99.1-100.2] & 1082 & 1170.5 & 0.92 & $0.87-0.98$ & 861 & 958.1 & 0.9 & $0.84-0.96$ & 198 & 191.3 & 1.04 & $0.90-1.19$ \\
\hline ]100.2-100.9] & 633 & 654.9 & 0.97 & $0.89-1.04$ & 534 & 537.1 & 0.99 & $0.91-1.08$ & 91 & 106.1 & 0.86 & $0.70-1.05$ \\
\hline ]100.9-105.5] & 920 & 955.2 & 0.96 & $0.90-1.03$ & 774 & 783.2 & 0.99 & $0.92-1.06$ & 129 & 154.8 & 0.83 & $0.70-0.99$ \\
\hline ]105.5-109.3] & 938 & 874.8 & 1.07 & $1.01-1.14$ & 771 & 716.8 & 1.08 & $1.00-1.15$ & 145 & 142.3 & 1.02 & $0.87-1.20$ \\
\hline ]109.3-123.9] & 925 & 903.6 & 1.02 & $0.96-1.09$ & 778 & 740.7 & 1.05 & $0.98-1.13$ & 140 & 146.6 & 0.96 & $0.81-1.13$ \\
\hline ]123.9-137,8] & 966 & 902.7 & 1.07 & $1.00-1.14$ & 805 & 739.6 & 1.09 & $1.02-1.17$ & 149 & 146.7 & 1.02 & $0.86-1.19$ \\
\hline Total & 9082 & 9082 & & & 7443 & 7443 & & & 1476 & 1476 & & \\
\hline$p$ for heterogeneity ${ }^{a}$ & & & 0.03 & & & & 0.01 & & & & 0.24 & \\
\hline$p$ for departure from log-linearity ${ }^{b}$ & & & 0.11 & & & & 0.09 & & & & 0.19 & \\
\hline \multirow[t]{2}{*}{ Trend by unit of $25 \mathrm{~J} / \mathrm{cm}^{2}$} & & & 1.06 & $1.01-1.11$ & & & 1.09 & $1.03-1.14$ & & & 0.97 & $0.86-1.08$ \\
\hline & \multicolumn{4}{|c|}{ Precursor B-cell ALL (PBC-ALL) } & \multicolumn{4}{|c|}{ Burkitt-cell Leukemia (B-ALL) } & \multicolumn{4}{|c|}{ T-cell ALL (T-ALL) } \\
\hline UV radiation deciles & 0 & E & SIR & $95 \% \mathrm{Cl}$ & 0 & $\mathrm{E}$ & SIR & $95 \% \mathrm{Cl}$ & 0 & $\mathrm{E}$ & SIR & $95 \% \mathrm{Cl}$ \\
\hline [85.5-90.3] & 581 & 599.8 & 0.97 & $0.89-1.05$ & 40 & 33.8 & 1.18 & $0.87-1.61$ & 122 & 106.2 & 1.15 & $0.96-1.37$ \\
\hline ]90.3-94.1] & 552 & 586.8 & 0.94 & $0.87-1.02$ & 52 & 33.1 & 1.57 & $1.20-2.06$ & 109 & 103.9 & 1.05 & $0.87-1.27$ \\
\hline ]94.1-97.2] & 571 & 594.3 & 0.96 & $0.89-1.04$ & 27 & 33.5 & 0.81 & $0.55-1.18$ & 98 & 104.9 & 0.93 & $0.77-1.14$ \\
\hline ]97.2-99.1] & 607 & 599.1 & 1.01 & $0.94-1.10$ & 24 & 33.5 & 0.72 & $0.48-1.07$ & 97 & 104.5 & 0.93 & $0.76-1.13$ \\
\hline ]99.1-100.2] & 666 & 773.8 & 0.86 & $0.80-0.93$ & 47 & 42.4 & 1.11 & $0.83-1.48$ & 136 & 131 & 1.04 & $0.88-1.23$ \\
\hline ]100.2-100.9] & 444 & 433 & 1.03 & $0.93-1.13$ & 25 & 23.9 & 1.05 & $0.71-1.55$ & 61 & 74.1 & 0.82 & $0.64-1.06$ \\
\hline ]100.9-105.5] & 615 & 628.5 & 0.98 & $0.90-1.06$ & 40 & 35.4 & 1.13 & $0.83-1.54$ & 112 & 110.4 & 1.01 & $0.84-1.22$ \\
\hline ]105.5-109.3] & 638 & 575.2 & 1.11 & $1.03-1.20$ & 24 & 32.4 & 0.74 & $0.50-1.11$ & 101 & 101 & 1.00 & $0.82-1.21$ \\
\hline ]109.3-123.9] & 653 & 593.4 & 1.1 & $1.02-1.19$ & 27 & 33.7 & 0.8 & $0.55-1.17$ & 93 & 105.3 & 0.88 & $0.72-1.08$ \\
\hline ]123.9-137.8] & 650 & 593.1 & 1.1 & $1.01-1.18$ & 29 & 33.5 & 0.87 & $0.60-1.25$ & 117 & 104.7 & 1.12 & $0.93-1.34$ \\
\hline Total & 5977 & 5977 & & & 335 & 335 & & & 1046 & 1046 & & \\
\hline \multirow{2}{*}{$\begin{array}{l}p \text { for heterogeneity }{ }^{\mathrm{a}} \\
p \text { for departure from log-linearity }\end{array}$} & \multicolumn{4}{|c|}{$<0.0001$} & \multicolumn{4}{|c|}{0.02} & \multicolumn{4}{|c|}{0.43} \\
\hline & \multicolumn{4}{|c|}{0.31} & \multicolumn{4}{|c|}{0.06} & \multicolumn{4}{|c|}{0.34} \\
\hline Trend by unit of $25 \mathrm{~J} / \mathrm{cm}^{2}$ & & & 1.12 & $1.03-1.22$ & & & 0.75 & $0.57-0.97$ & & & 1.00 & $0.87-1.15$ \\
\hline
\end{tabular}


$E=$ Expected number of cases; $\mathrm{O}=$ Observed number of cases; $\mathrm{SIR}$ and $95 \% \mathrm{Cl}=$ Standardized Incidence ratio and its $95 \%$ confidence interval

a $p$-value of the test for heterogeneity of the SIR observed across the 10 strata of UV radiation exposure; ${ }^{b}$-value of the test for departure from log-linearity of the SIR 
Table 3: Incidence of childhood lymphoma (ages 0-14) by decile of UV radiation exposure (France, 1990-2009)

\begin{tabular}{|c|c|c|c|c|c|c|c|c|c|c|c|c|}
\hline \multirow[b]{2}{*}{ UV radiation deciles $\left(\mathrm{J} / \mathrm{cm}^{2}\right)$} & \multicolumn{4}{|c|}{ Lymphoma } & \multicolumn{4}{|c|}{ Non-Hodgkin's lymphoma (NHL) } & \multicolumn{4}{|c|}{ Hodgkin's lymphoma (HL) } \\
\hline & 0 & $\mathrm{E}$ & SIR & $95 \% \mathrm{Cl}$ & 0 & $\mathrm{E}$ & SIR & $95 \% \mathrm{Cl}$ & 0 & $\mathrm{E}$ & SIR & $95 \% \mathrm{Cl}$ \\
\hline$[85.5-90.3]$ & 297 & 361.7 & 0.82 & $0.73-0.92$ & 176 & 212.2 & 0.83 & $0.72-0.96$ & 121 & 149.5 & 0.81 & $0.68-0.97$ \\
\hline ]90.3-94.1] & 384 & 354.4 & 1.08 & $0.98-1.20$ & 221 & 207.7 & 1.06 & $0.93-1.21$ & 163 & 146.8 & 1.11 & $0.95-1.29$ \\
\hline ]94.1-97.2] & 347 & 358.1 & 0.97 & $0.87-1.08$ & 192 & 209.9 & 0.91 & $0.79-1.05$ & 155 & 148.3 & 1.05 & $0.89-1.22$ \\
\hline ]97.2-99.1] & 334 & 355.3 & 0.94 & $0.84-1.05$ & 200 & 208.8 & 0.96 & $0.83-1.10$ & 134 & 146.5 & 0.91 & $0.77-1.08$ \\
\hline ]99.1-100.2] & 495 & 440.1 & 1.12 & $1.03-1.23$ & 291 & 260.8 & 1.12 & $0.99-1.25$ & 204 & 179.3 & 1.14 & $0.99-1.31$ \\
\hline ]100.2-100.9] & 257 & 249.8 & 1.03 & $0.91-1.16$ & 139 & 147.7 & 0.94 & $0.80-1.11$ & 118 & 102.1 & 1.16 & $0.97-1.38$ \\
\hline ]100.9-105.5] & 373 & 376.9 & 0.99 & $0.89-1.10$ & 221 & 221.0 & 1.00 & $0.88-1.14$ & 152 & 155.9 & 0.98 & $0.83-1.14$ \\
\hline ]105.5-109.3] & 346 & 345.1 & 1.00 & $0.90-1.11$ & 220 & 202.2 & 1.09 & $0.95-1.24$ & 126 & 143.0 & 0.88 & $0.74-1.05$ \\
\hline ]109.3-123.9] & 360 & 362.0 & 0.99 & $0.90-1.10$ & 222 & 211.1 & 1.05 & $0.92-1.20$ & 138 & 150.9 & 0.91 & $0.77-1.08$ \\
\hline ]123.9-137,8] & 370 & 359.6 & 1.03 & $0.93-1.14$ & 209 & 209.8 & 1.00 & $0.87-1.14$ & 161 & 149.9 & 1.07 & $0.92-1.25$ \\
\hline Total & 3563 & 3563 & & & 2091 & 2091 & & & 1472 & 1472 & & \\
\hline $\begin{array}{c}p \text { for heterogeneity }{ }^{a} \\
p \text { for departure from log-linearity }{ }^{b}\end{array}$ & & & $\begin{array}{l}0.01 \\
0.28\end{array}$ & & & & $\begin{array}{l}0.08 \\
0.09\end{array}$ & & & & $\begin{array}{l}0.03 \\
0.26\end{array}$ & \\
\hline \multirow[t]{2}{*}{ Trend by unit of $25 \mathrm{~J} / \mathrm{cm}^{2}$} & & & 1.05 & $0.94-1.17$ & & & 1.06 & $0.97-1.17$ & & & 1.02 & $0.88-1.20$ \\
\hline & \multicolumn{4}{|c|}{ Lymphoblastic-NHL } & \multicolumn{4}{|c|}{ Mature-NHL } & \multicolumn{4}{|c|}{ Burkitt-NHL } \\
\hline UV radiation deciles $\left(\mathrm{J} / \mathrm{cm}^{2}\right)$ & 0 & $\mathrm{E}$ & SIR & $95 \% \mathrm{Cl}$ & 0 & $\mathrm{E}$ & SIR & $95 \% \mathrm{Cl}$ & 0 & $\mathrm{E}$ & SIR & $95 \% \mathrm{Cl}$ \\
\hline$[85.5-90.3]$ & 32 & 49.3 & 0.65 & $0.46-0.92$ & 60 & 65.8 & 0.91 & $0.71-1.17$ & 83 & 96.6 & 0.86 & $0.69-1.07$ \\
\hline ]90.3-94.1] & 61 & 48.3 & 1.26 & $0.98-1.62$ & 73 & 64.4 & 1.13 & $0.90-1.43$ & 87 & 94.5 & 0.92 & $0.75-1.14$ \\
\hline ]94.1-97.2] & 49 & 48.8 & 1.00 & $0.76-1.33$ & 60 & 65.1 & 0.92 & $0.72-1.19$ & 83 & 95.5 & 0.87 & $0.70-1.08$ \\
\hline ]97.2-99.1] & 45 & 48.6 & 0.93 & $0.69-1.24$ & 55 & 64.6 & 0.85 & $0.65-1.11$ & 100 & 95.2 & 1.05 & $0.86-1.28$ \\
\hline ]99.1-100.2] & 70 & 60.9 & 1.15 & $0.91-1.45$ & 86 & 80.1 & 1.07 & $0.87-1.33$ & 134 & 119.3 & 1.12 & $0.95-1.33$ \\
\hline ]100.2-100.9] & 30 & 34.4 & 0.87 & $0.61-1.25$ & 44 & 45.4 & 0.97 & $0.72-1.30$ & 65 & 67.6 & 0.96 & $0.75-1.23$ \\
\hline ]100.9-105.5] & 54 & 51.5 & 1.05 & $0.80-1.37$ & 65 & 68.4 & 0.95 & $0.75-1.21$ & 101 & 100.7 & 1.00 & $0.83-1.22$ \\
\hline ]105.5-109.3] & 47 & 47.1 & 1.00 & $0.75-1.33$ & 78 & 62.7 & 1.24 & $1.00-1.55$ & 95 & 92.0 & 1.03 & $0.84-1.26$ \\
\hline ]109.3-123.9] & 56 & 49.2 & 1.14 & $0.88-1.48$ & 68 & 65.5 & 1.04 & $0.82-1.32$ & 98 & 96.0 & 1.02 & $0.84-1.24$ \\
\hline ]123.9-137,8] & 43 & 48.8 & 0.88 & $0.65-1.19$ & 58 & 65.1 & 0.89 & $0.69-1.15$ & 107 & 95.5 & 1.12 & $0.93-1.35$ \\
\hline Total & 487 & 487 & & & 647 & 647 & & & 953 & 953 & & \\
\hline$p$ for heterogeneity ${ }^{a}$ & \multirow{2}{*}{\multicolumn{4}{|c|}{$\begin{array}{l}0.12 \\
0.08\end{array}$}} & \multirow{2}{*}{\multicolumn{4}{|c|}{$\begin{array}{l}0.48 \\
0.39\end{array}$}} & \multicolumn{4}{|c|}{0.55} \\
\hline$p$ for departure from log-linearity ${ }^{b}$ & & & & & & & & & \multicolumn{4}{|c|}{0.81} \\
\hline Trend by unit of $25 \mathrm{~J} / \mathrm{cm}^{2}$ & \multicolumn{2}{|c|}{$\frac{0.08}{1.01}$} & 1.01 & $0.83-1.23$ & \multicolumn{4}{|r|}{$0.83-1.18$} & & & 1.14 & $0.99-1.31$ \\
\hline
\end{tabular}

$\mathrm{E}=$ Expected number of cases; $\mathrm{O}=$ Observed number of cases; $\mathrm{SIR}$ and $95 \% \mathrm{Cl}=$ Standardized Incidence ratio and its $95 \%$ confidence interval

${ }^{a} \mathrm{p}$-value of the test for heterogeneity of the SIR observed across the 10 strata of exposure to UV; ${ }^{b} \mathrm{p}$-value of the test for departure from log-linearity of the SIR 
Table 4: Association between UV radiation exposure and incidence of PBC-ALL by age group at diagnosis (France, 19902009)

\begin{tabular}{|c|c|c|c|c|c|c|c|c|c|c|c|c|}
\hline & \multicolumn{4}{|c|}{$0-4$ years old } & \multicolumn{4}{|c|}{ 5-9 years old } & \multicolumn{4}{|c|}{$10-14$ years old } \\
\hline $\begin{array}{c}\text { UV radiation deciles } \\
\left(\mathrm{J} / \mathrm{cm}^{2}\right)\end{array}$ & 0 & $E$ & SIR & $95 \% \mathrm{Cl}$ & 0 & $E$ & SIR & $95 \% \mathrm{Cl}$ & 0 & $E$ & SIR & $95 \% \mathrm{Cl}$ \\
\hline [85.5-90.3] & 336 & 337.7 & 0.99 & $0.89-1.11$ & 166 & 166.0 & 1.00 & $0.86-1.16$ & 79 & 96.1 & 0.82 & $0.66-1.02$ \\
\hline ]90.3-94.1] & 309 & 330.0 & 0.94 & $0.84-1.05$ & 165 & 162.4 & 1.02 & $0.87-1.18$ & 78 & 94.3 & 0.83 & $0.66-1.03$ \\
\hline ]94.1-97.2] & 320 & 334.6 & 0.96 & $0.86-1.07$ & 158 & 164.5 & 0.96 & $0.82-1.12$ & 93 & 95.2 & 0.98 & $0.80-1.20$ \\
\hline ]97.2-99.1] & 330 & 341.4 & 0.97 & $0.87-1.08$ & 177 & 164.2 & 1.08 & $0.93-1.25$ & 100 & 93.5 & 1.07 & $0.88-1.30$ \\
\hline ]99.1-100.2] & 387 & 454.0 & 0.85 & $0.77-0.94$ & 179 & 206.4 & 0.87 & $0.75-1.00$ & 100 & 113 & 0.88 & $0.73-1.07$ \\
\hline ]100.2-100.9] & 245 & 251.1 & 0.98 & $0.86-1.11$ & 121 & 117.3 & 1.03 & $0.86-1.23$ & 78 & 64.6 & 1.21 & $0.97-1.51$ \\
\hline ]100.9-105.5] & 343 & 355.4 & 0.97 & $0.87-1.07$ & 174 & 173.3 & 1.00 & $0.87-1.17$ & 98 & 99.8 & 0.98 & $0.81-1.20$ \\
\hline ]105.5-109.3] & 360 & 325.5 & 1.11 & $1.00-1.23$ & 171 & 158.2 & 1.08 & $0.93-1.26$ & 107 & 91.6 & 1.17 & $0.97-1.41$ \\
\hline ]109.3-123.9] & 371 & 331.8 & 1.12 & $1.01-1.24$ & 171 & 164.9 & 1.04 & $0.89-1.20$ & 111 & 96.8 & 1.15 & $0.95-1.38$ \\
\hline ]123.9-137.8] & 394 & 333.6 & 1.18 & $1.07-1.30$ & 159 & 163.7 & 0.97 & $0.83-1.13$ & 97 & 95.8 & 1.01 & $0.83-1.24$ \\
\hline Total & 3395 & 3395 & & & 1641 & 1641 & & & 941 & 941 & & \\
\hline $\begin{array}{l}\text { Heterogeneity } p^{a} \\
\text { Departure from log- } \\
\text { linearity } p^{b}\end{array}$ & & & $\begin{array}{c}0.0002 \\
0.11\end{array}$ & & & & $\begin{array}{l}0.68 \\
0.58\end{array}$ & & & & $\begin{array}{l}0.08 \\
0.16\end{array}$ & \\
\hline $\begin{array}{l}\text { Trend by unit of } 25 \\
\mathrm{~J} / \mathrm{cm}^{2}\end{array}$ & & & 1.18 & $1.10-1.27$ & & & 1.00 & $0.90-1.12$ & & & 1.15 & $1.00-1.32$ \\
\hline Trend with threshold $^{c}$ & & & 1.24 & $1.14-1.36$ & & & & & & & & \\
\hline
\end{tabular}

$\mathrm{E}=$ Expected number of cases; $\mathrm{O}=$ Observed number of cases; $\mathrm{SIR}$ and $95 \% \mathrm{Cl}=$ Standardized Incidence ratio and its $95 \%$ confidence interval

${ }^{a} \mathrm{p}$-value of the test for heterogeneity of the SIR observed across the 10 strata of UV radiation exposure; ${ }^{b} \mathrm{p}$-value of the test for departure from log-linearity of the SIR; 'Trend with threshold: the threshold value which achieved the best fit to the data was $100 \mathrm{~J} / \mathrm{cm}^{2}$, the UVT variable is therefore the excess of UV radiation (in units of $25 \mathrm{~J} / \mathrm{cm}^{2}$ ) above $100 \mathrm{~J} / \mathrm{cm}^{2}$, that is: UVT = 0 if UV $\leq 100 \mathrm{~J} / \mathrm{cm}^{2}$, UVT $=(U V$ $100) / 25$ if UV $\geq 100 \mathrm{~J} / \mathrm{cm}^{2}$ 
Table 5: Association between UV radiation exposure and incidence of PBC-ALL diagnosed before age 5 years in France 1990-2009, by time period and in 5 French regions

\begin{tabular}{|c|c|c|c|c|c|c|c|c|c|c|c|}
\hline Variable & Strata & $\operatorname{Min}^{a}$ & $\mathrm{P} 10^{\mathrm{a}}$ & Median $^{\text {a }}$ & $\mathrm{P} 90^{\mathrm{a}}$ & $\operatorname{Max}^{\mathrm{a}}$ & $\%$ pop $(<5$ years old $)>100 \mathrm{~J} / \mathrm{cm}^{2}$ & 0 & $\mathrm{E}$ & SIR & $95 \% \mathrm{Cl}$ \\
\hline \multirow[t]{3}{*}{ Periods } & 1990-1996 & 85.5 & 90.3 & 100.0 & 123.4 & 137.8 & 50.0 & 1176 & 1176 & 1.20 & $1.03-1.39$ \\
\hline & 1997-2003 & 85.5 & 90.4 & 100.2 & 123.6 & 137.8 & 51.0 & 1145 & 1145 & 1.29 & $1.11-1.49$ \\
\hline & 2004-2009 & 85.5 & 90.5 & 100.2 & 123.6 & 137.8 & 51.7 & 1074 & 1074 & 1.24 & $1.06-1.45$ \\
\hline \multirow[t]{5}{*}{ Geographic areas } & South-East & 93.8 & 103.5 & 116.5 & 130.8 & 137.8 & 96.0 & 852 & 784.5 & 1.25 & $1.07-1.45$ \\
\hline & South-West & 96.9 & 103.2 & 109.2 & 113.7 & 123.7 & 97.5 & 426 & 394.8 & 1.67 & $0.88-3.20$ \\
\hline & Paris area ${ }^{b}$ & 97.3 & 99.1 & 100.2 & 100.9 & 101.7 & 54.8 & & & - & \\
\hline & North-West & 88.2 & 93.0 & 97.6 & 104.4 & 117.8 & 26.3 & 685 & 682.5 & 1.12 & $0.59-2.11$ \\
\hline & North-East & 85.5 & 88.7 & 91.2 & 98.1 & 112.1 & 2.7 & 800 & 828.2 & 0.29 & $0.003-24.53$ \\
\hline Overall association & France 1990-2009 & 85.5 & 90.3 & 100.2 & 123.5 & 137.8 & 50.9 & 3395 & 3395 & 1.24 & $1.14-1.36$ \\
\hline
\end{tabular}

$\mathrm{O}=$ Observed number of cases; $\mathrm{E}$ = expected number of cases; SIR = Estimated trend in SIR by unit of a $25 \mathrm{~J} / \mathrm{cm}^{2}$ above $100 \mathrm{~J} / \mathrm{cm}^{2}$ obtained from the slope of the adjusted Poisson regression of Observed over Expected number of cases as a linear function of Commune UVT exposure, with UVT $=0$ if UV $\leq 100 \mathrm{~J} / \mathrm{cm}^{2}, \mathrm{UVT}=(\mathrm{UV}-100) / 25$ if UV $\left.\geq 100 \mathrm{~J} / \mathrm{cm}^{2}\right)$; ${ }^{\text {a }} \mathrm{UV}$ radiation distribution per stratum weighted by the population aged less than 5 years; ${ }^{b}$ Paris was excluded because of the very low variability of the UV radiation distribution in that area 


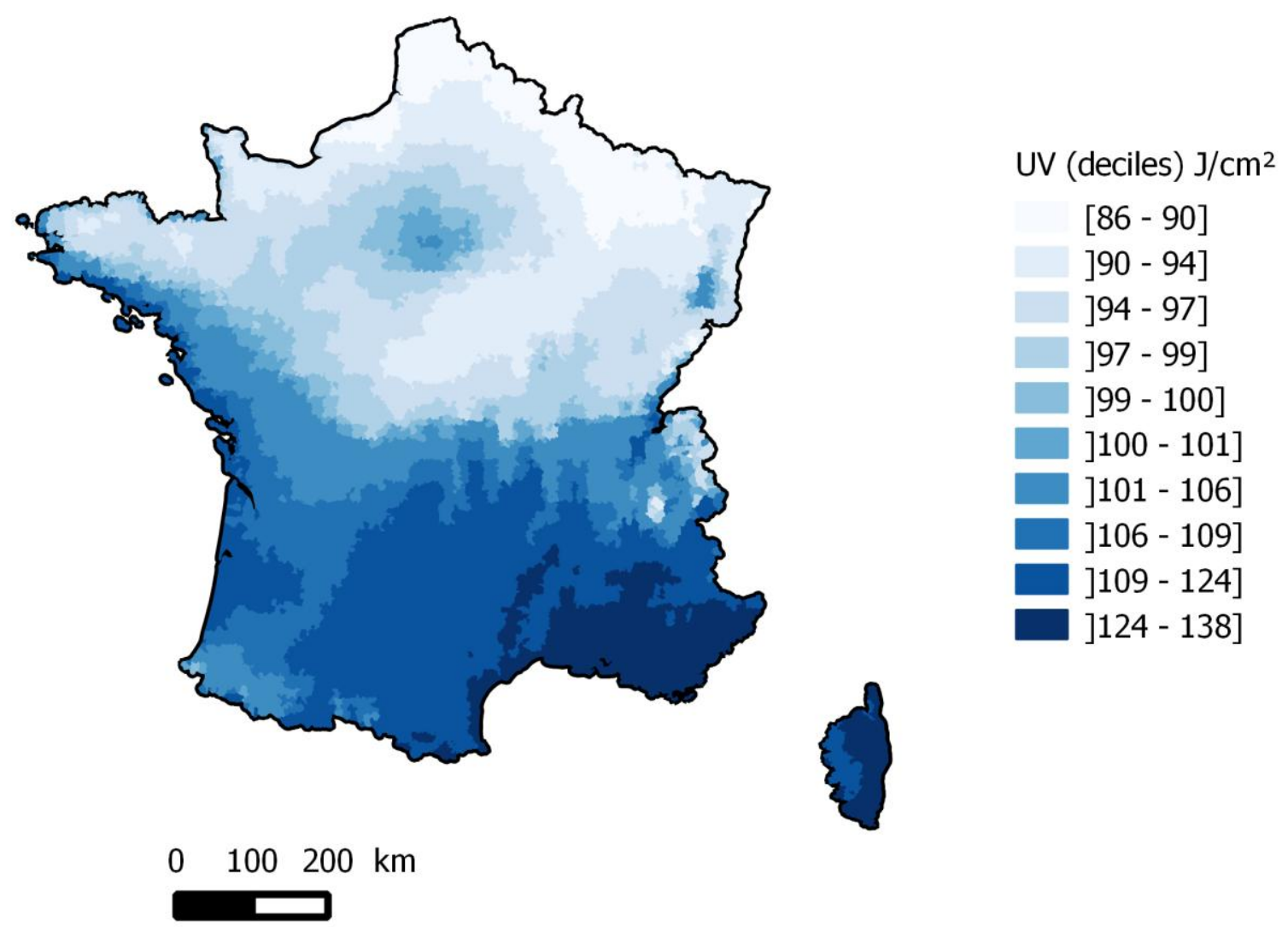

Figure 1: UV radiation: spatial variations in France, $1988-2007\left(\mathrm{~J} / \mathrm{cm}^{2}\right)^{\text {a }}$ 
Supplementary table A: Association between UV radiation exposure and ALL incidence by age group at diagnosis (France, 1990-2009)

\begin{tabular}{|c|c|c|c|c|c|c|c|c|c|c|c|c|}
\hline & \multicolumn{4}{|c|}{$0-4$ years old } & \multicolumn{4}{|c|}{ 5-9 years old } & \multicolumn{4}{|c|}{$10-14$ years old } \\
\hline $\begin{array}{c}\text { UV radiation } \\
\text { deciles }\left(\mathrm{J} / \mathrm{cm}^{2}\right)\end{array}$ & 0 & $E$ & SIR & $95 \% \mathrm{Cl}$ & 0 & $E$ & SIR & $95 \% \mathrm{Cl}$ & 0 & $E$ & SIR & $95 \% \mathrm{Cl}$ \\
\hline [85.5-90.3] & 380 & 375.9 & 1.01 & $0.91-1.12$ & 236 & 230.3 & 1.02 & $0.90-1.16$ & 135 & 142.4 & 0.95 & $0.80-1.12$ \\
\hline ]90.3-94.1] & 353 & 367.2 & 0.96 & $0.87-1.07$ & 238 & 225.3 & 1.06 & $0.93-1.20$ & 134 & 139.7 & 0.96 & $0.81-1.14$ \\
\hline ]94.1-97.2] & 354 & 372.2 & 0.95 & $0.86-1.06$ & 210 & 228.0 & 0.92 & $0.80-1.05$ & 141 & 141.0 & 1.00 & $0.85-1.18$ \\
\hline ]97.2-99.1] & 362 & 379.7 & 0.95 & $0.86-1.06$ & 239 & 227.6 & 1.05 & $0.93-1.19$ & 138 & 138.4 & 1.00 & $0.84-1.18$ \\
\hline ]99.1-100.2] & 442 & 504.8 & 0.88 & $0.80-0.96$ & 261 & 285.7 & 0.91 & $0.81-1.03$ & 158 & 167.7 & 0.94 & $0.81-1.10$ \\
\hline ]100.2-100.9] & 265 & 279.2 & 0.95 & $0.84-1.07$ & 159 & 162.4 & 0.98 & $0.84-1.14$ & 110 & 95.5 & 1.15 & $0.96-1.39$ \\
\hline ]100.9-105.5] & 380 & 395.2 & 0.96 & $0.87-1.06$ & 243 & 240.1 & 1.01 & $0.89-1.15$ & 151 & 147.9 & 1.02 & $0.87-1.20$ \\
\hline ]105.5-109.3] & 399 & 361.9 & 1.10 & $1.00-1.22$ & 224 & 219.2 & 1.02 & $0.90-1.17$ & 148 & 135.7 & 1.09 & $0.93-1.28$ \\
\hline ]109.3-123.9] & 403 & 368.9 & 1.09 & $0.99-1.20$ & 230 & 228.5 & 1.01 & $0.88-1.15$ & 145 & 143.2 & 1.01 & $0.86-1.19$ \\
\hline ]123.9-137.8] & 438 & 371.0 & 1.18 & $1.08-1.30$ & 234 & 227.0 & 1.03 & $0.91-1.17$ & 133 & 141.6 & 0.94 & $0.79-1.11$ \\
\hline Total & 3776 & 3776 & & & 2274 & 2274 & & & 1393 & 1393 & & \\
\hline $\begin{array}{l}\text { Heterogeneity } \\
\qquad=^{a} \\
\text { Departure from } \\
\text { log-linearity } p={ }^{b}\end{array}$ & & & $\begin{array}{c}0.0004 \\
0.12\end{array}$ & & & & $\begin{array}{l}0.79 \\
0.71\end{array}$ & & & & $\begin{array}{l}0.83 \\
0.76\end{array}$ & \\
\hline $\begin{array}{c}\text { Trend by unit of } \\
25 \mathrm{~J} / \mathrm{cm}^{2}\end{array}$ & & & 1.16 & $1.08-1.25$ & & & 1.02 & $0.93-1.11$ & & & 1.00 & $0.89-1.13$ \\
\hline
\end{tabular}

$\mathrm{E}=$ Expected number of cases; $\mathrm{O}=$ Observed number of cases; $\mathrm{SIR}$ and $95 \% \mathrm{Cl}=$ Standardized Incidence ratio and its $95 \%$ confidence interval; ${ }^{a} p$-value of the test for heterogeneity of the SIR observed across the 10 strata of UV radiation exposure; ${ }^{b} p$-value of the test for departure from log-linearity of the SIR 
Supplementary table B: Association between UV radiation exposure and childhood ALL incidence by gender (France, 1990-2009)

\begin{tabular}{|c|c|c|c|c|c|c|c|c|}
\hline & \multicolumn{4}{|c|}{ Boys } & \multicolumn{4}{|c|}{ Girls } \\
\hline $\begin{array}{c}\text { UV radiation } \\
\text { deciles }\end{array}$ & 0 & $\bar{E}$ & SIR & $95 \% \mathrm{Cl}$ & 0 & $\bar{E}$ & SIR & $95 \% \mathrm{Cl}$ \\
\hline$[85,5-90,3]$ & 429 & 422.0 & 1.02 & $0.92-1.12$ & 322 & 326.6 & 0.99 & $0.88-1.10$ \\
\hline ]90,3-94,1] & 423 & 411.7 & 1.03 & $0.93-1.13$ & 302 & 320.6 & 0.94 & $0.84-1.05$ \\
\hline ]94,1-97,2] & 390 & 416.5 & 0.94 & $0.85-1.03$ & 315 & 324.7 & 0.97 & $0.87-1.08$ \\
\hline ]97,2-99,1] & 426 & 418.8 & 1.02 & $0.93-1.12$ & 313 & 326.8 & 0.96 & $0.86-1.07$ \\
\hline ]99,1-100,2] & 484 & 536.4 & 0.90 & 0.83-0.99 & 377 & 421.7 & 0.89 & $0.81-0.99$ \\
\hline ]100,2-100,9] & 286 & 300.8 & 0.95 & $0.85-1.07$ & 248 & 236.3 & 1.05 & 0.93-1.19 \\
\hline$] 100,9-105,5]$ & 439 & 440.5 & 1.00 & $0.91-1.09$ & 335 & 342.7 & 0.98 & $0.88-1.09$ \\
\hline ]105,5-109,3] & 403 & 403.3 & 1.00 & $0.91-1.10$ & 368 & 313.5 & 1.17 & $1.06-1.30$ \\
\hline ]109,3-123,9] & 440 & 416.9 & 1.06 & $0.96-1.16$ & 338 & 323.8 & 1.04 & $0.94-1.16$ \\
\hline ]123,9-137,8] & 463 & 416.3 & 1.11 & $1.02-1.22$ & 342 & 323.3 & 1.06 & $0.95-1.18$ \\
\hline Total & 4183 & 4183 & & & 3260 & 3260 & & \\
\hline $\begin{array}{c}\text { Heterogeneity } p={ }^{a} \\
\text { Departure from } \\
\log \text {-linearity } p={ }^{b}\end{array}$ & & & $\begin{array}{l}0.10 \\
0.30\end{array}$ & & & & $\begin{array}{l}0.03 \\
0.10\end{array}$ & \\
\hline $\begin{array}{l}\text { Trend by unit of } \\
25 \mathrm{~J} / \mathrm{cm}^{2}\end{array}$ & & & 1.08 & $1.01-1.16$ & & & 1.09 & $1.01-1.18$ \\
\hline
\end{tabular}

$\mathrm{E}=$ Expected number of cases; $\mathrm{O}=$ Observed number of cases; $\mathrm{SIR}$ and $95 \% \mathrm{Cl}=$ Standardized Incidence ratio and its $95 \%$ confidence interval; ${ }^{a} p$-value of the test for heterogeneity of the SIR observed across the 10 strata of UV radiation exposure; ${ }^{b} p$-value of the test for departure from log-linearity of the SIR 
Supplementary figure: Standardized Incidence Ratio (SIR) of PBC-ALL diagnosed before age 5 years in France, 1990-2009, as a function of the UV radiation exposure of the Commune of residence at diagnosis

Observed SIR with $95 \% \mathrm{CI}$ by UV radiation decile and SIR predicted from the fitted threshold linear model

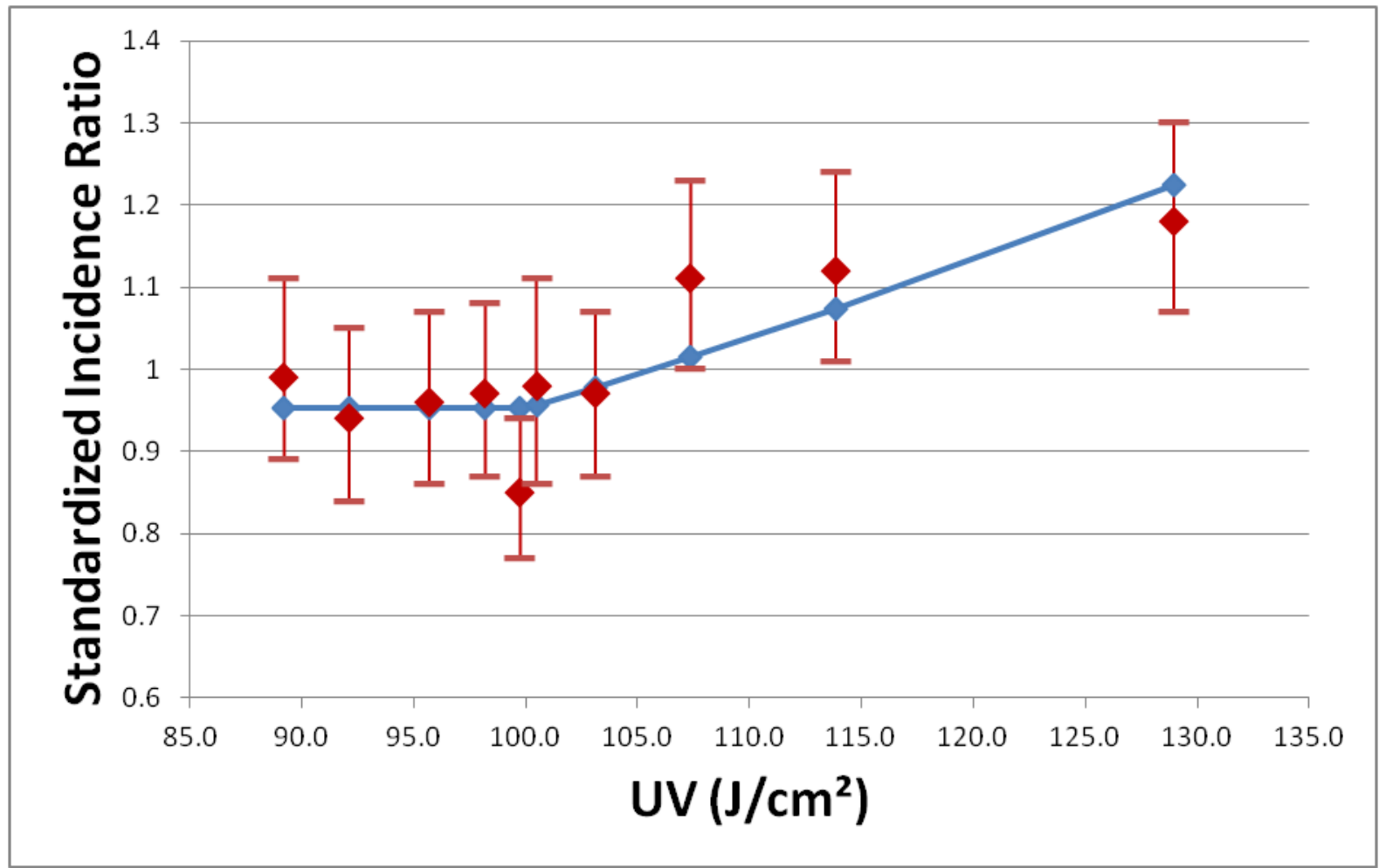

${ }^{\mathrm{a}}$ Vertical bars: Observed SIR and $95 \%$ confidence limits

${ }^{\mathrm{b}}$ Continuous line: SIR predicted by the model with the best fit (log-linear model with threshold at $100 \mathrm{~J} / \mathrm{cm}^{2}$ ) 